Pak. j. sci. ind. res. Ser. B: biol. sci. 2018 61B(3) 182-186

\title{
Review
}

\section{Probable Ingredients for Trans Free Margarine with Omega-3 Fatty Acids}

\author{
Muhammad Ajmal, Muhammad Nadeem*, Maryam Batool and Imran Taj Khan \\ Department of Dairy Technology, University of Veterinary and Animal Sciences, Lahore, Pakistan
}

(received October 20, 2015; revised July 25, 2017; accepted July 31, 2017)

\begin{abstract}
Margarine is widely used as table spread, in cooking and bakery products. Awareness of consumers regarding the intake of omega fatty acids has led the food industry to develop foods which are rich sources of omega fatty acids. Harmful effects of trans on the development of cardiovascular diseases have steered the researchers to find out wide range of trans free options, without compromising on functional and physical properties of fats. Nutritionists recommend margarine for the growing and school going babies, it is usually manufactured from the combination of hard and soft fats, followed by the addition of vitamins A, D and E. However, little is known regarding the supplementation of margarines with omega fatty acids of chia oil. This paper summarizes the physical and chemical characteristics of few ingredients that may be used in the formulation of trans free margarine with higher magnitude of omega fatty acids.
\end{abstract}

Keywords: margarine, omega fatty acids, trans free, chia oil

\section{Introduction}

Margarine is usually prepared from vegetable fats, the feedstock may originate from partially hydrogenated, interesterified and transesterified. Different categories of margarine are produced at industrial level e.g. table margarine, bakery margarine etc. According to the Codex Standards, margarine should contain at least $80 \%$ fat and $16 \%$ moisture at maximum (Codex, 2001). Margarine is used as an alternate source of butter. It can be manufactured from a wide range of materials including a combination of hydrogenated and nonhydrogenated stuffs (Richmond, 2007). Ever increasing population has led to a great deal of increase in the production of margarine during the last few decades. Now a days, most of the margarines are made from hydrogenated oils, partial hydrogenation of oil can induce trans fatty acids which have many health hazards (Shahidi, 2005). The partial hydrogenation of vegetable oils chemically transforms some of the unsaturated fats into the novel forms of trans-fatty acids leading to an increase in the proportion of saturated fats in these oils. Trans fatty acids are not required for any biochemical function in human body (Richmond, 2007). Health benefits associated with the intake of omega-3 margarine fortified foods is well known. Increased knowledge of food connected health ailments has considerably

*Author for correspondence; E-mail:

muhammad.nadeem@uvas.edu.pk increased the demand of functional foods. Healthful properties of margarine can be improved through the fortification of omega-3 fatty acids with trans free options. Food is the basic requirement of life. Therefore, it should be safe. Scientific studies have proved that foods are directly related with many diseases such as cancer, cardiovascular diseases, obesity and hypertension etc. (Astrup et al., 2011). Functional foods are getting popularity all over the world and researchers are trying to utilize the non-traditional sources of foods to develop functional foods with added health advantages (KrisEtherton et al., 2002). This paper summarizes the physical and chemical characteristics of ingredients that can be used in the formulation of trans free margarine with numerous health benefits of omega-3 fatty acids.

Chemical composition of margarine. Fat content in margarine ranges from 80 to $90 \%$. Margarine is a waterin-oil emulsion and fat phase is a network of fat crystals and agglomerates of fat with liquid oil entrapped in between. Ingredients like fat soluble flavours, vitamins, colourants and emulsifiers are the contents of fatty phase of margarine. Aqueous phase contains maximum $16 \%$ of water and remaining $4 \%$ are water-soluble ingredients. To produce the desired quality margarine, it is favourable to have optimum processing and desirable fat blending. Types of margarine are dependent on the solid fat content, melting point of fat, structure and characteristics of margarine (Vereecken, 2010). 
Trans fatty acids. Most of trans fatty acids enter in body through the intake of partially hydrogenated fats. There is scientific evidence that trans fatty acids are not necessary for any physiological function of the human body (Lokuruka, 2007). The concentration of trans fatty acids in partially hydrogenated fats depends upon temperature and hydrogen gas pressure. Higher the concentration of nickel catalyst, temperature, gas pressure and catalyst dose, greater would be the degree of geometric isomerization (Shahidi, 2005). As per recommendation of American Heart Association, intake of trans fatty acids should not be more than $2 \mathrm{~g}$ / day (AHA, 2000). In USA, coronary heart disease is the most common killer, many people are suffering from high blood pressure, stroke and rheumatic fever, with about $41.2 \%$ deaths due to cardiovascular diseases (AHA, 2000). Nadeem et al. (2014) reported that the concentration of trans fatty acids in partially hydrogenated fat was more than $21 \%$. The existence of a strong correlation between harmful HDL cholesterol and trans fatty acids has led to the development of large number of trans free options. Nadeem et al. (2017) showed that margarine prepared from palm oil, palm kernel oil and chia oil blends trans fatty acids in margarine. Use of fractionation, inter esterification, trans esterification and blending of fats and oils in appropriate ratios can lead to the successful manufacturing of margarine, partially hydrogenated fat (used commonly in subcontinent) and shortening with similar plasticity, melting point and solid fat index without partial hydrogenation (O'Brien, 2008). Karabulut and Tauran (2006) analyzed 15 types of margarine available in Turkey and showed that concentration of trans fatty acids ranged from $8.5 \%$ to as high as $39 \%$. Oil processing industries have started focusing on the development of blends which have higher concentration

Table 1. Fatty acid composition of chia oil and some vegetable oils

\begin{tabular}{lllll}
\hline \hline Fatty acid & $\begin{array}{l}\text { Chia } \\
\text { oil }\end{array}$ & $\begin{array}{l}\text { Sunflower } \\
\text { oil }\end{array}$ & $\begin{array}{l}\text { Soybean } \\
\text { oil }\end{array}$ & $\begin{array}{l}\text { Canola } \\
\text { oil }\end{array}$ \\
\hline C16:0 & 9.6 & 6.5 & 10.2 & 3.8 \\
C18:0 & 4.3 & 1.8 & 3.8 & 4.2 \\
C18:1 & 6.8 & 3.9 & 22.8 & 63.7 \\
C18:2 & 17.6 & 68.1 & 52.8 & 16.4 \\
C18:3 & 64.1 & 1.2 & 7.6 & 9.5 \\
Reference & Jin et al. & O'Brien & Shahidi & Anwar \\
& (2012) & $(2008)$ & $(2005)$ & et al. \\
& & & & (2007) \\
\hline \hline
\end{tabular}

of beneficially unsaturated fatty acids with lower/zero trans to minimize the risk of cardiovascular diseases (Miskandar et al., 2005).

Chemical characteristics of chia oil. Chia (Salvia hispanica L.) is native to Mexico; it was the staple food in Mexico in pre-historic times. It is an emerging oil seed crop that contains about $35-40 \%$ praise worthy oil. Chia oil contains $\alpha$-linolenic acid up to $68 \%$ (Ayerza, 1995). Chia oil also contains significant concentrations of natural antioxidant such as chlorogenic acid, caffeic acid, myricetin, quercetin and kaempferol (ReyesCaudillo et al., 2008).

Chia oil a powerhouse of beneficial omega fatty acids. Omega-3 poly unsaturated fatty acid are essential fatty acids, which must be consumed through the diet (Nadeem et al., 2017). Chia oil is a great source of Omega-3 and Omega-6 fatty acids, which are essential for proper development and functioning of brain and it is also cellular component within the body (Jin et al., 2012). Chia oil is the most efficient source of omega3 fatty acids. This omega- 3 fatty acids obtained from fish have fishy flavour, which limits the application of omega-3 fatty acids in large number of foods. Whereas, omega-3 fatty acids obtained from chia oil is not associated with any flavour defect and unfavourable physiological function (Ayerza et al., 2002). Chia seeds have high content of omega-3 fatty acids, which have been implicated in the reduction of cholesterol level. They prevents blood clotting, improve tissue regeneration, control sugar level in blood, diabetes, cardiovascular diseases, regulate the immune system and development of retina and brain (Vuksan et al., 2007). Eicosapentaenoic acid and decosapentaenoic acid prevent the cardiovascular disease and their daily recommendation is $500 \mathrm{mg}$ for cardiovascular disease risk reduction (Gebauer et al., 2006). A number of medical and epidemiological studies demonstrated that consumption of lipids that contain omega-3 fatty acids reduce the risk of cardiovascular disease (Zhao et al., 2004). Chia oil has good oxidative stability, it was the part of Mexican diet in pre-historic times (BeltranOrozco and Romero, 2003). Increased intakes of omega fatty acids have been related with low cholesterol level in blood, reduces the blood pressure, prevent the growth of tumors and also decreases the risk of heart attack (Ruiz-Rodriguez et al., 2010). Omega-3 fatty acids are anti-carcinogenic, anti-atherogenic, anti-lipogenic, prevent the hypertension, control immune disorders and 
possess immuno-suppressive properties (Williams, 2000). Omega-3 fatty acids have antiarrhythmic, antithrombotic, anti-inflammatory and vasodilator properties. It may also prevent type- 2 diabetes and insulin resistance (Lombardo and Chicco, 2006). Docosahexaenoic acid (DHA) which contains 22 carbons and 6 double bonds is the largest unsaturated fatty acid in human body. DHA has been related to alleviation of a number of human illnesses, including heart diseases, cancers and neurological disorders (Stillwell et al., 2006). DHA is the major structural fatty acid in nervous system and retina. Pregnant and nursing women should take about $2.6 \mathrm{~g}$ of omega- 3 fatty acids and $100-300 \mathrm{mg}$ of DHA on daily basis. The intake DHA during preschool years may also have a beneficial role in prevention of attention deficit hyperactivity disorder and increase learning ability and academic concern (Gebauer et al., 2006). Concentration of omega- 3 fatty acids in margarine can be increased through chia oil, which is a rich source of beneficial omega-3 fatty acids. Nadeem et al. (2016a) blended milk fat with high oleic acid fraction of Moringa oleifera oil, blends had higher magnitude of unsaturated fatty acids with no trans fatty acids. Nadeem et al. (2016b) added interesterified Moringa oleifera oil in ice cream, physical and oxidative stability characteristics of ice cream were improved without generation of harmful trans fatty acids.

Milk fat. Milk fat is usually regarded as precious fat for having appreciable amounts of short-chain fatty acids. The rich natural aroma of milk fat is mainly the contribution of short-chain fatty acids (McSweeney and Fox, 2003). It also contains about $22-26 \%$ oleic acid, with scientifically proven health benefits. Further, fats having an appreciable amount of oleic acid are getting a high degree of fame because of large number of health benefits and superior oxidative stability. Fatty acids and triglycerides composition of milk fat restricts its application in large number of bakery and other food products. Milk is mainly used in the manufacturing of butter and butter oil, whereas, partially hydrogenated fats have a wide range of applications in large number of food products (Deffense, 2002). Milk fat is good source of essential fatty acids and fat-soluble vitamins (A, D, E, and K). Short-chain fatty acids in milk fat are mainly responsible for superior sensory characteristics of dairy products, use of milk fat in margarine may improve the sensorial. Milk fat also contains about 1.5$2 \%$ omega- 6 fatty acids and $0.5-0.7 \%$ omega- 3 fatty acid (Nadeem et al., 2017; 2016a)
Palm oil. Palm oil has melting point $37-39{ }^{\circ} \mathrm{C}$ and iodine value is 50-55 (Nadeem et al., 2017). Palm oil is solid at room temperature which allows its application in large number of food preparations, such as Vanaspati, margarine, bakery and cake shortenings etc. without partial hydrogenation and generation of trans fatty acids. Palm oil is used worldwide in margarine manufacturing and also food products as an ingredient. Palm oil is most important for food industry in manufacturing of trans free margarine (Gillespie, 2012). Fatty acid (about $50 \%$ saturated and $50 \%$ unsaturated) and triglyceride composition of palm oil suggest wide range of trans free options (Mukherjee and Mitra, 2009). It is rich source of palmitic acid (44\%), oleic acid about (40\%) and stearic acid 5\%. It has high oxidative stability and possesses reasonable amounts of antioxidants like betacarotene (DeGraef, 2009). It has beneficial health perspectives as it contains no trans free fat, high betacarotene and vitamin E (Henderson and Osborne, 2000). Palm oil has superior thermal stability, therefore, it can be successfully added into large number of bakery products (Foster et al., 2009).

\section{Conclusion}

Margarine may be produced from wide range of trans free options, such as blending, inter esterification, trans esterification etc. Palm oil, palm olein, palm kernel oil and milk fat may be used for the preparation of trans free margarine. Concentration of omega-3 fatty acids in margarine may be improved with chia oil.

\section{Acknowledgement}

Financial assistance for this project was provided by Higher Education Commission of Pakistan (HEC/4947/NRPU).

\section{References}

AHA,2000. Cholesterol.Heart and Stroke Guide. American Heart Association. <http://www. americanheart. org.com $>$ (17 April, 2001).

Anwar, F., Hussain, A.I., Iqbal, S., Bhanger, M.I. 2007. Enhancement of the oxidative stability of some vegetable oils by blending with Moringa oleifera oil. Food Chemistry, 103: 1181-1191.

Astrup, A., Dyerberg, J., Elwood, P., Hermansen, K., Hu, F.B., Jakobsen, M.U., Kok, F.J., Krauss, R.M., Lecerf, J.M., LeGrand, P., Nestel, P., Riserus, U., Sanders, T., Sinclair, A., Stender, S., Tholstrup, T., Willett, W.C. 2011. The role of reducing intakes 
of saturated fat in the prevention of cardiovascular disease: where does the evidence stand in 2010? American Journal of Clinical Nutrition, 93: 684688.

Ayerza, R., Coates, W., Lauria, M. 2002. Chia as an omega-3 fatty acid source for broilers influence on fatty acid composition, cholesterol and fat content of white and dark meat, on growth performance and on meat flavour. Poultry Science, 81: 826-837.

Ayerza, R. 1995. Oil content and fatty acid composition of chia (Salvia hispanica L.) from five northwestern in Argentina. Journal of American Oil Chemists Society, 72:1079- 1081.

Beltran-Orozco, M.C., Romero, M.R. 2003. La chia, alimento milenario. Mexico, Departamento de Graduados e Investigacion en Alimentos, E. N. C. B., I. P. N, Mexico.

Codex Alimentarius. 2001. Codex general standard for margarine. vol 8, $2^{\text {nd }}$ edition, FAO \& WHO, Remo, Italy.

DeGraef, V. 2009. Microstructural Properties of Isothermal Palm Oil Crystallization. PhD Thesis. Ghent University, Belgium. 181pp.

Deffense, E. 2002. Fractionation of butterfat, In: Oils and Fats Series, Ch.5. Dairy Fats, Edn. B. Rossell.

Foster, R., Williamson, C.S., Lunn, J. 2009. Culinary oils and their health effects. Nutrition Bulletin, 34: 4-47.

Gebauer, S.K., Psota, T.L., Harris, W.S., Kris-Etherton, P.M. 2006. Omega-3 fatty acid dietary recommendations and food sources to achieve essentiality and cardiovascular benefits. American Journal of Clinical Nutrition, 83: S1526.

Gillespie, P. 2012. The challenges of corporate governance in Indonesian oil palm opportunities to move beyond legalism? Asian Studies Review, 36: $247-269$.

Henderson, J., Osborne, D.J. 2000. The oil palm in all our lives: how this came about. Endeavour, 24: 63-68.

Jin, F., Nieman, D.C., Sha, W., Xie. G., Qiu, Y., Jia, W. 2012. Supplementation of milled chia seeds increases plasma ALA and EPA in postmenopausal women. Plant Foods for Human Nutrition, 67: 105-110.

Kamla-Raj. 2009. Health effects of palm oil. Journal of Human Ecology, 26: 197-203.

Karabulut, I., Tauran, S. 2006. Some properties of margarines and shortenings marketed in Turkey. Journal of Food Composition and Analysis, 19:
55-58.

Kris-Etherton, P.M., Hecker, K.D., Bonanome, A., Coval, S.M., Binkoski, A.E., Hilpert, K.F., Griel, A.E., Etherton, T.D. 2002. Bioactive compounds in foods: their role in prevention of cardiovascular disease and cancer. American Journal of Medicine, 113: 71-88.

Lokuruka, M.N.I. 2007. Role of fatty acids of milk and dairy products in cardiovascular diseases: A review. African Journal of Food, Agriculture, Nutrition and Development. 7: 1-16.

Lombardo, Y., Chicco, A.G. 2006. Effects of dietary polyunsaturated omega-3 fatty acids on dyslipidemia and insulin resistance in rodents and humans. A review. Journal of Nutrition and Biochemistry, 17: 1-13.

McSweeney, Paul, L.H., Fox, P.F. 2003. Advanced Dairy Chemistry, Proteins. Parts A\&B, vol. 1, ${ }^{\text {rd }}$ edition, Kluwer Academic Plenum Pub, NY, USA.

Miskandar, M.S., Che Man, Y.B., Yusoff, M.S.A., Rahmann, R.A. 2005. Quality of margarine: fats selection and processing parameters. Asia Pacific Journal of Clinical Nutrition, 14: 387-395.

Mukherjee, S., Mitra, A. 2009. Health effects of palm oil. Journal of Human Ecology, 26: 197-203.

Nadeem, M., Imran, I., Taj, I., Ajmal, M., Junaid, M., 2017. Omega-3 fatty acids, phenolic compounds and antioxidant characteristics of chia oil supplemented margarine. Lipids in Health and Disease, 16: 102 .

Nadeem, M., Rahman Ullah. 2016a. Enhancement of oleic acid in butter oil by high oleic fraction of Moringa oleifera oil. Pakistan Journal of Scientific and Industrial Research. Ser. B: biol. sci. 59: 105110.

Nadeem, M., Rahman Ulla and Ansar Ullah. 2016b. Improvement of the physical and oxidative stability characteristics of ice cream through Interesterified Moringa oleifera oil. Pakistan Journal of Scientific and Industrial Research. Ser. B: biol. sci. 59: 3843.

Nadeem, M., Situ, C., Mahmud, A., Khalique, A., Imran, M., Rahman, F., Khan, S., 2014. Antioxidant activity of sesame (Sesamum indicum L.) cake extract for the stabilization of olein based butter. Journal of the American Oil Chemists Society, 91: 967- 977.

O' Brien, R.D. 2008. Fats and Oils: Formulating and Processing for Application. $3^{\text {rd }}$ edition, 680 pp., CRC Press; Taylor \& Francis Group, FL, USA.

Reyes-Caudillo, E., Tecante, A., Valdivia-López, M.A. 
2008. Dietary fibre content and antioxidant activity of phenolic compounds present in Mexican chia (Salvia hispanica L.) seeds. Food Chemistry, 107: 656-663.

Richmond, H.D. 2007. Dairy Chemistry, A Practical Handbook for Dairy Chemists and Others having Control of Dairies. $3^{\text {rd }}$ edition, C Griffin \& Co., London, UK.

Ruiz-Rodriguez, A., Reglero, G., Ibanez, E. 2010. Review-recent trends in the advanced analysis of bioactive fatty acids. Journal of Pharmacy and Biomedicine Analysis, 51:305-326.

Shahidi, S. 2005. Baileys 'Industrial Edible Oil and Fat Products. $6^{\text {th }}$ edition, John Wiley and Sons, Pub. Co., NY, USA.

Singh, M. 2003. Nutrition, brain and environment. How to have smarter Babies? Indian Pediatrics, 40: 213220.

Stillwell, W., Shaikh, S.R., LoCascio, D., Siddiqui, R.A., Seo, J., Chapkin, R.S., Wassall, S.R., Hauppage. 2006. The role of polyunsaturated lipids in membrane raft function. Scandinavian Journal of Food and Nutrition, 50: 107-113

Vereecken, J. 2010. Effect of Acylglycerol Composition on the Microstructural and Functional Properties of Bakery Fats and Margarines. Ph.D Thesis, Ghent University, Belgium. 251pp.

Vuksan, V., Whitman, D., Sievenpiper, J., Jenkins, A., Rogovik, A., Bazinet, R., Vidgen, E., Hanna, A. 2007. Supplementation of conventional therapy with the novel grain Salba (Salvia hispanica L.) Improves major and emerging cardiovascular risk factors in type 2 diabetes. Diabetes Care, 30: 2804 2810.

Williams, C.M. 2000. Dietary fatty acids and human health. Annales de Zootechnie, 49: 165-180.

Zhao, G., Etherton, T.D., Martin, K.R., West, S.G., Gillies, P.J., Kris-Etheron, P.M. 2004. Dietary linolenic acid reduces inflammatory and lipid cardiovascular risk factors in hypercholesterolemic men and women. Journal of Nutrition, 134: 2991-2997. 